\title{
PESQUISAS PÓS-CRÍTICAS EM EDUCAÇÃO NO BRASIL: ESBOÇO DE UM MAPA
}

\author{
MARLUCY ALVES PARAÍSO \\ Faculdade de Educação da Universidade Federal de Minas Gerais \\ maparaiso@bol.com.br
}

\begin{abstract}
RESUMO
As correntes teóricas que conhecemos sob os rótulos de pós-estruturalismo e de pós-modernismo influenciaram profundamente, como sabemos, as teorizações e as pesquisas em diversos campos das ciências sociais e humanas nos últimos anos; uma influência que tem sido igualmente considerável na pesquisa em educação no Brasil. Os efeitos combinados dessas correntes, sintetizados talvez na chamada "virada lingüística", expressam-se naquilo que se convencionou chamar de "teorias pós-críticas em educação". Em seu conjunto, essas teorias utilizam uma série de ferramentas conceituais, de operações analíticas e de processos investigativos que as destacam tanto das teorias tradicionais como das teorias críticas que as precederam. Este artigo discute os efeitos dessas teorias sobre a pesquisa educacional brasileira. Traçando uma espécie de esboço de um mapa do campo dos estudos pós-críticos em educação no Brasil, este artigo mostra o início das discussões pós-críticas no campo educacional brasileiro, discute as principais temáticas exploradas por essas pesquisas e indica os principais traçados por elas efetuados, descrevendo as expansões, as fraturas, as conquistas e as aberturas produzidas no campo educacional brasileiro.
\end{abstract}

PESQUISAEDUCACIONAL - PÓS-MODERNO_EDUCAÇÃO-BRASIL

\section{ABSTRACT}

POST-CRITICAL RESEARCHONEDUCATIONINBRAZIL: OUTLININGAMAP. The theoretical currents we know under the post-structuralism and the post-modernism labels have deeply influenced theorization and research in several social and human fields in the last years; an influence that has been equally felt in educational research in Brazil. The combined effects of these currents, possibly synthesized in the so-called "linguistic turn", are expressed in what is conventionally named "post-critical theories in education". As a whole, these theories use a number of conceptual tools, analytical operations, and investigative processes which differentiate them both from the traditional and from the critical theories which preceded them. This article discusses the effects of these theories on Brazilian educational research. Outlining a kind of field map of post-critical studies in education in Brazil, this article shows the beginning of post-critical discussions in the Brazilian educational field, addresses the key issues explored by these studies and indicates the main pathways they laid out, describing expansions, fractures, achievements, and breakthroughs produced in the Brazilian educational field.

EDUCATIONAL RESEARCH - POST-MODERN - EDUCATION - BRAZIL 
As correntes teóricas que conhecemos sob os rótulos de pós-estruturalismo e de pós-modernismo influenciaram profundamente, como sabemos, as teorizações e as pesquisas em diversos campos das ciências sociais e humanas nos últimos anos; uma influência que tem sido igualmente considerável na pesquisa em educação no Brasil. Os efeitos combinados dessas correntes, sintetizados talvez na chamada "virada lingüística", expressam-se naquilo que se convencionou chamar de "teorias pós-críticas em educação". Em seu conjunto, essas teorias utilizam uma série de ferramentas conceituais, de operações analíticas e de processos investigativos que as destacam tanto das teorias tradicionais como das teorias críticas que as precederam.

Este artigo tem por objetivo discutir os efeitos dessas teorias sobre a pesquisa educacional brasileira. Ele indica alguns traçados dessas pesquisas e descreve expansões, fraturas, conquistas e aberturas, esboçando uma espécie de mapa do campo dos estudos pós-críticos em educação no Brasil. Encontramos nesse mapa um conjunto de linhas dispersas, funcionando todas ao mesmo tempo, em velocidades variadas. Um mapa, segundo Deleuze (1992, p. 46-47), é aberto, conectável, composto de diferentes linhas, suscetível de receber modificações constantemente. Isso significa dizer que um campo que está sendo mapeado não se encontra fechado, acabado. Ele está sempre aberto a outras construções e significações. Nesse sentido, enquanto faço esse esboço de mapa, as pesquisas póscríticas em educação no Brasil estão movimentando-se, e podem estar fazendo outros contornos e atribuindo outros sentidos às questões educacionais brasileiras.

Cabe registrar que se as pesquisas educacionais pós-críticas constituem sistemas abertos, compostos por linhas variadas, elas também compõem linhas, tomam emprestado algumas e criam outras. É precisamente isso que mostro neste texto. Mostro as linhas traçadas pelas pesquisas pós-críticas em educação no Brasil, os encontros, as invenções e as problematizações feitas. Mostro seu caráter experimental e explicito suas composições e conexões. Argumento que essas pesquisas têm-se expandido no Brasil e incorporado uma variedade de linguagens oriundas de diferentes autores e teorias incluídas nas "teorias pós-críticas".

Usando uma linguagem que recebe influências da chamada "filosofia da diferença", do pós-estruturalismo, do pós-modernismo, da teoria queer, dos estudos feministas e de gênero, dos estudos multiculturalistas, pós-colonialistas, étnicos, ecológicos etc., as teorias pós-críticas realizam, no campo educacional brasileiro, substituições, rupturas e mudanças de ênfases em relação às pesquisas críticas. Suas produções e invenções têm pensado práticas educacionais, currículos e pedagogias 
que apontam para a abertura, a transgressão, a subversão, a multiplicação de sentidos e para a diferença.

Para a realização deste estudo mapeei, prioritariamente, as pesquisas e os ensaios divulgados nos encontros anuais da Associação Nacional de Pós-graduação e Pesquisa em Educação - ANPEd. Além disso, incorporei na análise aqueles livros que sabia, seguramente, tratarem da educação segundo perspectivas pós-críticas e que considerei importantes para mapear o impactodessas teorias nos estudos e pesquisas em educação no Brasil'.

Tracei um marco: o início de apresentação de trabalhos que adotam perspectivas pós-críticas na ANPEd em 1993, e analisei todo o percurso até 2003. Até 1992 não encontrei nas programações da ANPEd referências às questões coloca-

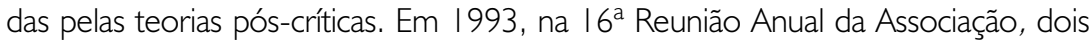
trabalhos são apresentados (Silva, 1993a; Santos, 1993). $\bigcirc$ primeiro, discute as questões centrais do pensamento pós-moderno e pós-estruturalista, mostrando as continuidades e as rupturas em relação à pedagogia e à sociologia críticas. $\bigcirc$ segundo, por sua vez, discute as relações entre poder e conhecimento com base na noção poder-saber de Michel Foucault.

Nesse ano identifica-se outro marco: um livro, Teorias educacionais críticas em tempos pós-modernos, que introduz as discussões pós-críticas no terreno educacional brasileiro. Organizado por Tomaz Tadeu da Silva (1993b), reuniu oito ensaios sobre o debate em torno das relações entre o pós-modernismo e a teoria educacional. Passando em revista as contribuições de autores como Baudrilhard, Derrida, Foucault, Lyotard, Rorty, entre outros, os ensaios mapearam as diferentes formas pelas quais o questionamento pós-moderno e pós-estrutural afeta o pensamento crítico em educação.

Em 1994, ampliam-se os trabalhos apresentados na ANPEd com essa perspectiva e um outro livro, O sujeito da educação: estudos foucaultianos (Silva, 1994a), divulga estudos que trabalham com o pensamento de Michel Foucault na análise da educação. Esse livro reuniu doze trabalhos escritos em uma perspectiva

I Muitos trabalhos apresentados na ANPEd foram, em seguida, publicados em revistas ou como capítulo de livros. Optei sempre nesses casos por citá-los como "trabalhos apresentados na ANPEd" por dois motivos: I. porque é no livro com programa e resumos da reunião que ele aparece primeiro, já que se exige para a apresentação de trabalho nesse evento que o texto seja inédito; 2. pela importância que a ANPEd tem no Brasil como espaço de divulgação de pesquisas em educação. 
foucaultiana de análise da educação por pesquisadores/as educacionais de várias partes do mundo. Pelas referências citadas nos diferentes trabalhos publicados nos anos seguintes pelos/as pesquisadores/as brasileiros/as, é possível dizer que esse livro teve grande influência nos estudos e nas investigações em educação que trabalham com perspectivas pós-críticas. Ele foi, certamente, um importante fator no processo de divulgação, disseminação e multiplicação das pesquisas pós-críticas em educação no Brasil.

\section{CONTÁGIO}

A partir desses estudos introdutórios de perspectivas pós-críticas em educação divulgadas no Brasil, existe uma espécie de contágio(Deleuze; Guattari, 1997, p. 23) dessas teorias nas pesquisas educacionais brasileiras, provocado pelas discussões iniciais. Aparece, no terreno educacional, uma multiplicidade de pesquisas e trabalhos que pensam a educação, a pedagogia, o currículo e outras práticas educativas de modo diferente do que até então vinha sendo pensado. Tais trabalhos passam a utilizar outras categorias para pensar e fazer a pesquisa em educação no Brasil. De modo geral, eles apontam para a abertura e a multiplicação de sentidos, para a transgressão e a subversão daquilo que anteriormente já havia sido significado no campo educacional.

As pesquisas pós-críticas em educação no Brasil explicitam aquilo que não constitui objeto de seus interesses: não gostam de explicações universais, nem de totalidades, nem de completudes ou plenitudes. Em vez disso, optam claramente por explicações e narrativas parciais, pelo local e pelo particular (Silva, 1993a). Não se preocupam com comprovações daquilo que já foi sistematizado na educação, nem com "revelações" ou "descobertas". Preferem a invenção, a criação, o artefato, a produção (Corazza, 200 I). Não acreditam na "suposta" autonomia do sujeito ou da subjetividade, à qual nós da educação não cansávamos de apegar-nos. Consideram o sujeito um efeito da linguagem, dos textos, do discurso, da história, dos processos de subjetivação (Silva, 1999).

Além disso, essas pesquisas não se interessam por modos "certos" de ensinar, formas "adequadas" de avaliar ou por conhecimentos "legítimos"; a não ser para problematizar essas comprovações, esses modos, essas formas e conhecimentos (Paraíso, 2003). Alguns trabalhos nessa perspectiva procuram mostrar que nas investigações pós-críticas encontram-se muitas possibilidades de entender e explicar o currículo, a pedagogia, os sujeitos da educação, o conhecimento escolar, as políticas 
educacionais, os processos de avaliação, os artefatos tecnológicos etc. (Silva, 1996 , 2003; Corazza, 200I).

Assim, como conseqüência de seus interesses, as pesquisas pós-críticas em educação no Brasil têm questionado o conhecimento (e seus efeitos de verdade e de poder), o sujeito (e os diferentes modos e processos de subjetivação), os textos educacionais (e as diferentes práticas que estes produzem e instituem). Tais pesquisas têm problematizado as promessas modernas de liberdade, conscientização, justiça, cidadania e democracia, tão difundidas pelas pedagogias críticas brasileiras² abdicado da exclusividade da categoria classe social e discutido, também, questões de gênero, etnia, raça, sexualidade, idade (Louro, 1995). Têm discutido questões dos tempos e espaços educacionais, mostrando os processos de feitura da escola moderna, bem como pensado, de diferentes formas, a diferença, a identidade e a luta por representação. Têm aberto mão da função de prescrever, de dizer aos outros como devem ser, fazer e agir. Têm, acima de tudo, buscado implodir e radicalizar a crítica àquilo que já foi significado na educação, e procurado fazer aparecer o que não estava ainda significado.

Observando os trabalhos e livros iniciais e percorrendo os seus traçados, acompanhando os seus trajetos e sua capacidade ou não de proliferação, é possível dizer que eles conduzem pesquisadores e pesquisadoras, inicialmente, à realização de sínteses das perspectivas pós-críticas e à problematização de conhecidas questões educacionais com base nos aportes da crítica pós-estruturalista. Em uma espécie de "experimentação" dessas teorias, são realizados, em um primeiro momento, nos estudos e pesquisas pós-críticos em educação no Brasil, dois movimentos. Um deles sintetiza e divulga as potencialidades analíticas das teorias pós-críticas para pensar questões da educação no Brasil, o que pode ser visto em Silva (1994, 1995), Louro (1994), Fischer (1994) e Veiga-Neto (1994, 1995, 1996), por exemplo. Outro movimento se fez no sentido de experimentar as teorias pós-críticas para discutir diferentes objetos do campo educacional: o construtivismo pedagógico (Corazza, 1994), o conhecimento didático (Ogiba, 1994), as metodologias participativas de pesquisas (Costa, 1995), as reformas educacionais (Marzola, 1995), a educação ambiental (Grun, 1995), a produção do feminino e do masculino nas práticas escolares (Louro, 1995).

2 A exemplo da pedagogia crítica de inspiração freireana (proposta de educação popular de Paulo Freire) e a pedagogia crítico-social dos conteúdos, proposta por Dermeval Saviani. 
São produzidos, também nesse período, inúmeros trabalhos que discutem questões de procedimentos de pesquisa e modos de pesquisar em educação inspirados nas teorias pós-críticas. Isso pode ser visto, entre outros, em: Costa (1996), Costa e Grun (1996), Corazza (1996), Beatriz Fischer (1996), Rosa Fischer (1996, 1998), Louro (1996), Ogiba et al. (1996) e Veiga-Neto (1996). Tais trabalhos exploram as posturas e os caminhos investigativos, as "ferramentas" e operações analíticas adotadas em pesquisas que trabalham com questões de gênero, com os estudos feministas, com os estudos culturais, com os estudos negros, com o pensamento de Michel Foucault e que operam com diferentes conceitos das teorias pós-críticas de um modo geral. São mostrados nesses trabalhos os procedimentos adotados por pesquisadores/as que trabalham nesse território, "onde olham", "como e por que olham” (Costa, 1996). São expostos, assim, suas escutas, seus próprios olhares e as ferramentas, as precauções e as inspirações daqueles/as que fazem pesquisas em educação trabalhando com essas perspectivas. Defende-se, nesses trabalhos, a produtividade de posturas investigativas e ferramentas analíticas de inspiração pós-crítica para olhar de modo diferente a educação e para fazer aparecer o que não está ainda significado nesse território.

Em síntese, os objetivos da maioria dos estudos e trabalhos divulgados no período do contágio, que vem imediatamente após os traçados iniciais, parecem ser: divulgar os desafios teóricos e políticos colocados pelas teorias pós-críticas, mostrar a importância para a educação de seus argumentos e das questões por elas tratadas, e contribuir para criar caminhos investigativos e saídas metodológicas para escapar das totalizações e homogeneizações das metanarrativas, buscando possibilidades para pesquisar que utilizem o singular, o local e o parcial.

\section{LINHAS E CONTORNOS DOS ESTUDOS PÓS-CRÍTICOS}

procedimento seguinte das pesquisas e dos ensaios analisados é explorar detalhadamente alguns conceitos e proposições do pensamento pós-crítico, em uma busca incansável pela produção de novos sentidos na educação. Mesmo sabendo que corro o risco de cometer uma certa "violência" com os trabalhos analisados, ao agrupar pesquisas e estudos que talvez não devessem ser agrupados, faço esses agrupamentos para apresentar um panorama geral daquilo que é enfocado pelos estudos e pesquisas pós-críticos em educação no Brasil. Desse modo, sempre tendo em vista essa ressalva, talvez possa dizer que as linhas mais exploradas pelas pesquisas pós-críticas sejam: 
I. a das relações de poder na educação;

2. a do sujeito (identidade, subjetividade e modos de subjetivação);

3. a da descrição e análise da artificialidade da produção de saberes na educação (conhecimentos, verdades, discursos) ${ }^{3}$.

É importante registrar que ainda que estejam no mesmo território (o território dos estudos e das pesquisas pós-críticas em educação), alguns trabalhos encontramse muito afastados entre si. Algumas linhas traçadas são exploradas, estendidas, traçadas de outros modos. Outras linhas parecem desmancharem-se logo que traçadas. Algumas fazem contornos. Outras demarcam diferenças. Outras ainda parecem sumir no silêncio dado em resposta à sua força de inquietação. Algumas linhas proliferam. Outras não aumentam sua potência e não há continuidade nos seus traçados iniciados. Talvez porque, naquele momento, as linhas tenham sido fortes, vivas e cortantes demais.

De todo modo, nem todas as pesquisas proliferam, ainda que tenham força suficiente para deixar os/as educadores/as incomodados/as, por muito tempo, em relação à temática abordada e aos argumentos apresentados. Assim, por exemplo, a linha da "desconstrução do construtivismo pedagógico" (Silva, 1993b) ou da análise do próprio "construtivismo pedagógico como significado transcendental do currículo" (Corazza, 1994), com inspiração nos trabalhos de Jacques Derrida, não tem continuidade no território analisado. Os trabalhos sobre o construtivismo, analisado com base em perspectivas pós-críticas, só são retomados no campo educacional brasileiro tempos depois em um livro, organizado por Silva (1998a), no qual o construtivismo é abordado com base em conceitos foucaultianos, e apenas dois, dos sete ensaios que compõem o livro, são de autores brasileiros.

Já as linhas das relações de poder na educação (inspiradas no pensamento de Michel Foucault) e das identidades subjugadas (inspiradas nos estudos culturais, nos estudos feministas, pós-coloniais, étnicos e na teoria queer), ao contrário, são estendidas e exploradas de diferentes modos. Elas contagiam, multiplicam-se e proliferam de diferentes formas no território analisado. Vejamos com mais detalhe essas linhas que proliferaram no território das pesquisas pós-críticas em educação no Brasil.

3 Ainda que parte das pesquisas pós-críticas em educação no Brasil lide com todos esses domínios, faço uma separação para fins didáticos e para mostrar melhor o que tais pesquisas procuram explorar, produzir, significar. 
As noções de poder e discurso de Michel Foucault, com seu caráter produtivo e constitutivo, são exploradas nas discussões de diferentes objetos. São discutidas, por exemplo, as relações de poder envolvidas "na relação intelectuaismovimentos sociais" (Knijnik, 1995), na "produção de sujeitos masculinos e cristãos em projetos educacionais específicos" (Louro, 1995a), nas tecnologias avaliativas da observação, da auto-avaliação e dos pareceres descritivos em processos avaliativos (Corazza, 1996a), na "vontade de cidadania" do discurso da educação matemática (Bampi, 1999), no processo de reforma curricular no ensino superior (Mendes, 1998), nas pedagogias críticas brasileiras (Garcia, 2000), na fabricação do sujeito infantil (Bujes, 2000), no discurso educacional da mídia educativa brasileira (Paraíso, 200I) e na produção de verdades sobre a infância em projetos de informática educativa (Sommer, 2000) etc. Como se vê, essas linhas das relações de poder foram discutidas considerando os mais diferentes objetos no campo educacional. Elas contagiaram, proliferaram, multiplicaram-se.

Contudo é importante destacar que, embora explorem as relações de poder em diferentes práticas discursivas, objetos e espaços educativos, essas pesquisas não se deixam aprisionar nas amarras das ações do poder identificadas e analisadas. Considerando que existem problemas a serem resolvidos, tarefas a serem realizadas e territórios a serem conquistados, essas pesquisas atuam na zona do indeterminado e aí fazem problematizações, interrogações e questionamentos. Problematizam as identidades que são referências em diferentes práticas educativas (Louro, 1997). Interrogam sobre "o lugar do currículo numa paisagem pós-moderna", tendo em vista os novos mapas culturais traçados pela emergência de uma multiplicidade de atores sociais e por um ambiente tecnicamente modificado (Silva, 1995b). Questionam "as relações entre currículo, identidade e poder" (Silva, 1995) e, portanto, as múltiplas formas pelas quais o currículo está centralmente envolvido na produção do social.

É interessante notar que a linha da identidade, ou melhor, essas linhas traçadas que discutem a questão das identidades sociais rebeladas e das lutas políticas por representação (Silva, 1996, 1998a) também são retomadas de diferentes modos, contagiando, proliferando, povoando. São problematizados a arrogância, os silêncios, "os segredos e as mentiras" do currículo sexista, generificado, urbano, etnocêntrico, e com uma sexualidade padrão" (Paraíso, 1995, 1996, 1997, 1998; Louro, 1998; Meyer, 1998). São explicitados "os binarismos do currículo urbano que exclui as culturas de colonos/as migrantes" (Reali, 1996). São discutidas práticas educativas e diferentes textos que produzem identidades de tipos específicos: "o bom moço e a 
boa moça" (Fraga, 1998), "profissionais femininas do magistério" (Costa, 1998), "o surdo trabalhador" (Klein, 1998).

Ainda nessa mesma linha, são analisadas as representações de docência teutobrasileiro-evangélica, imbricadas na proposição e manutenção de um programa específico de formação de professores/as (Meyer, 2000). São examinados os modos pelos quais as representações culturais de raça e gênero constituem a masculinidade dos homens negros que participam de um grupo religioso afro-católico específico (Parente, 2000). Uma multiplicidade de análises, explorações e discussões seguindo essa linha da representação e das identidades (com base sobretudo nas discussões pós-estruturalistas dos estudos culturais) é encontrada no terreno educacional. Essa linha continua sendo estendida pelas pesquisas pós-críticas em educação. Ela, até a atualidade, é de fato a linha que mais tem sido explorada pelas pesquisas pós-críticas em educação no Brasil.

Contudo, cabe registrar que, dando continuidade à linha da produção de sujeitos, a própria noção de identidade é questionada. Subverte-se e "complica" a identidade por meio de maior ênfase no conceito de diferença (Silva, 2000b). Além disso, essa linha da produção de sujeitos faz no território das pesquisas pós-críticas em educação outros contornos e outros traçados, trazendo outras marcas, outros referenciais teóricos e outros procedimentos de análise. Assim, seja perseguindo a idéia da "Pedagogia dos monstros" (Donald, 2000a) ou da "subjetividade ciborgue" (Donald 2000; Silva 2000a, 2000), seja utilizando a noção de governo de Michel Foucault para mostrar como nossas subjetividades são reguladas (Corazza, 200 l; Silva, 200la), as pesquisas educacionais no Brasil mostram que o processo de formação da subjetividade é muito mais complicado do que nos fazem crer os pressupostos sobre o "sujeito" que constituem o núcleo das teorias pedagógicas críticas ou tradicionais.

Nessa perspectiva, exploram-se as linhas das subjetividades e dos modos de subjetivação em diferentes pesquisas. Tem-se freqüentemente perguntado nesse tipo de pesquisa: "como nos tornamos o que somos?"; "que técnicas e tecnologias são acionadas na produção de determinados tipos de sujeitos?"; "por que queremos que alguém se torne um sujeito de um certo tipo?". E, nesse caso, têm sido descritos "enunciados" e perseguidas as "técnicas de dominação e técnicas de si" (com inspiração, sobretudo, no pensamento de Michel Foucault), para mostrar o processo de produção de sujeitos de certos tipos: "crítico", "construtivista", "amigo da escola", "livre", "heterossexual", "afetuoso" etc. Existe aí um encontro das linhas da subjetividade e do sujeito com as linhas do poder ou das relações de poder que 
explicam como as coisas, os objetos e os sujeitos são construídos, formados, impondo-se como "verdades da educação".

Nesse sentido, nas pesquisas pós-críticas, exploram-se as produções de sujeitos de diferentes modos. Analisa-se a "fabricação" da subjetividade docente psicocrítica, produzida por técnicas psicológicas movidas por impulsos libertários, disseminada nas pedagogias construtivistas (Silva, 1998). Examina-se a constituição de um tipo de subjetividade moderna produzida por saberes e discursos médicos (Stephanou, 1998). Investigam-se os modos de subjetivação do infantil, discutindo a fratura da subjetividade infantil moderna e os novos modos de enunciação do infantil (Corazza, 1999). São analisados os saberes divulgados na cultura de massa que instituem a subjetividade feminina sintetizada nas figuras de "princesas": mulheres reais ou fictícias que se apresentam como "adequadas" e "belas" (Gomes, 1999). São explorados os estragos produzidos na subjetividade humana depois do pós-estruturalismo, mostrando como o "ciborgue" põe em xeque a ontologia do humano (Silva, 2000a). Expõe-se a artificialidade do tipo de sujeito "de consciência crítica" produzido pelas pedagogias críticas, mostrando a sua produção histórica (Silva, 2000) etc.

Além disso, seguindo a linha da subjetividade e expandindo seus materiais de análise, as pesquisas pós-críticas, sensíveis aos problemas educacionais vivenciados pelos praticantes da educação, expandem suas críticas a diferentes textos e artefatos. Nessas pesquisas, explora-se a subjetividade libertadora fabricada por textos de Paulo Freire (Cardarelho, 2000) e a subjetividade crítica produzida pelas pedagogias críticas brasileiras (Garcia, 2000). Discute-se a produção, na mídia educativa brasileira, de sujeitos pedagógicos afetivos, solidários, "amigos da escola" e co-responsáveis pelo processo educacional de crianças e jovens (Paraíso, 200I). Investiga-se a constituição do infantil logogizador (Santos, 2000). Analisa-se ainda o governo moral do infantil pelos Parâmetros Curriculares Nacionais (Uberti, 2000), e se expõem os processos de constituição de diferentes tipos de sujeitos na cultura de massa contemporânea (Fischer, 200 I).

Ampliando os materiais e textos investigados, analisam-se as estratégias e as técnicas de poder-saber utilizadas pelos jogos eletrônicos para educar os jogadores de determinados modos, produzindo um tipo de sujeito jogador (Mendes, 2002). Investiga-se o investimento feito sobre a subjetividade docente pelo currículo da mídia educativa brasileira, para divulgar uma subjetividade docente amorosa, corajosa, afetuosa, empreendedora e solidária, capaz de driblar todos os problemas que encontrar na educação escolar (Paraíso, 2002). Problematiza-se a política de 
subjetividade da infância na atualidade por meio da análise da economia de controle da subjetividade em um programa da mídia televisiva (Uberti, 2003).

Em síntese, os sujeitos produzidos em diferentes práticas e por diferentes textos constituem linhas que são constantemente traçadas, retraçadas e que fazem encontros no território das pesquisas pós-críticas em educação no Brasil. É preocupação dessas pesquisas expor o tipo de sujeito e de subjetividade que as diferentes práticas educativas formam, modificam, educam, fabricam, fixam, divulgam. Reunidas, essas pesquisas mostram que o sujeito (ou a subjetividade) é produzido, montado ou fabricado em diferentes práticas discursivas (tanto na escola como fora dela) que se combinam ou não para a regulação das nossas condutas. Defendem que o sujeito não existe fora da história, da linguagem, do discurso e das relações de poder. Enfim, mostram que é preciso estudar as diferentes práticas que investem uma infinidade de técnicas, estratégias e procedimentos na produção de certos tipos de sujeitos e de determinados "objetos".

Uma outra linha perseguida pelas pesquisas pós-críticas constitui-se no questionamento e na problematização de todas as "verdades" educacionais, inclusive daquelas que nos acostumamos a considerar "boas" porque caracterizadas como "democráticas", "libertadoras", "transformadoras", "cidadãs" etc. Essas pesquisas expõem o caráter de objeto construído, fabricado, produzido dos "objetos da educação": o/a professor/a, a pedagogia, o currículo, a escola, o/a aluno/a etc. Nesse processo, as verdades, os conhecimentos, os saberes da pedagogia, do currículo e da educação tornam-se objetos de problematização. Os estudos destacam o caráter artificial de verdades curriculares, de saberes educacionais, de conhecimentos considerados legítimos. Trata-se de pesquisas que explicitam os processos pelos quais as verdades são produzidas, os saberes inventados, os conhecimentos construídos. Evidencia-se, assim, o processo de fabricação de "objetos", "coisas" e práticas na educação. Pergunta-se: por que esses conhecimentos em vez de outros?; por que essas formas em vez de outras?; por que esses saberes em vez de outros?; por que essas práticas em vez de outras? Persegue-se o seu processo de produção, o funcionamento, o "como" tais conhecimentos, formas e saberes tornaram-se verdadeiros.

Nesse sentido, essas linhas e esses traçados problematizam, de diferentes modos, os conhecimentos curriculares "legítimos". Os estudos questionam os motivos que nos levam a considerar certos tipos de conhecimento mais desejáveis que outros, certos tipos de sujeitos melhores do que outros e alguns valores e saberes preferíveis a outros (Silva, 200 I). Seguindo e estendendo essa linha de 
investigação de diferentes textos e materiais que nos educam de diferentes modos, problematiza-se a ambição da interdisciplinaridade, que se propõe a solucionar o problema da compartimentalização do saber escolar, e se discute a possível transversalidade dos saberes no currículo (Gallo, 1995, 1996). Analisa-se a política cultural da avaliação como possuindo funções estratégicas na política cultural da infância e dos saberes escolares (Corazza, 1995). Focaliza-se a poética e a política do currículo como representação interessada de diferentes grupos sociais e culturais (Silva, 1998a).

Ainda nessa mesma linha, são discutidos os exercícios escolares e seu papel estratégico na produção de conhecimentos escolares (Amorin, 2000). É investigada a produção da noção de espaço e tempo escolares em um filme hollywoodiano (Fabris, 1998). É analisada a produção de um tipo de currículo de formação de professores na televisão que ensina às/aos docentes como devem ser, fazer e viver (Paraíso, 2000). É investigada a produção do currículo multicultural no discurso da etnomatemática (Bampi, 200 I).

As pesquisas pós-críticas, seguindo linhas e contornos já criados ou traçando novas linhas, variam os focos de investigação, inventam, criam, discutem. Inventam o currículo como fetiche (Silva, 1999), o currículo como linguagem (Corazza, 200 I), - currículo como prática de significação (Silva, 1999a), o currículo como representação (Silva, 1999b), o currículo como máquina desejante (Kroef, 200 I), o currículo-mapa (Paraíso, 2003), o currículo vagamundo (Corazza, 2003). Discutemse as conexões entre o pensamento de Nietzsche e as atuais tendências teóricas representadas pelo pós-estruturalismo e pela filosofia da diferença para exercitar o pensar sobre uma teoria do currículo (Silva, 200 la). Discute-se a fusão existente entre os currículos "alternativos" e "oficiais", mostrando que nossas propostas atuais estão no espaço "entre" o oficial e o alternativo (Corazza, 2000). Descrevem-se algumas práticas etnomatemáticas como tecnologias de governo de cidadãos e cidadãs (Bampi, 2000).

Finalizando esse mapeamento das pesquisas pós-críticas em educação no Brasil, cabe registrar que tais pesquisas mais uma vez estão movimentando-se, procurando variar os conceitos e as teorias para pensar questões educacionais. Recen-

4 Essa linha da transversalidade dos saberes no currículo escolar, discutida e analisada com base em conceitos de Gilles Deleuze e Félix Guattari e, portanto, em uma perspectiva póscrítica, não tem continuidade de análise nessa perspectiva. Ela é retomada e citada por pesquisadores/as da educação que trabalham com outras perspectivas, como a crítica, por exemplo. 
temente, no território das pesquisas pós-críticas em educação, diferentes pesquisadores/as têm procurado experimentar conceitos e procedimentos de pesquisas retirados da Filosofia da Diferença, especialmente os estudos de Gilles Deleuze e Félix Guattari, para pesquisar e discutir temas da educação. Em 2002 a revista Educação e Realidade dedicou um número inteiro a trabalhos que pensam a educação com base nas produções desses autores 5 .

São sete artigos de autores de diferentes países e sete artigos de pesquisadores/as brasileiros/as que pensam a pedagogia da sala de aula, a docência, o currículo, a infância, a política educacional etc.

Desse modo, as pesquisas pós-críticas em educação têm feito o currículo, a pedagogia, o ensino e outras práticas educativas movimentarem-se. Ao "atirar flechas" e realizar investigações que perseguem as condições de invenção dos conhecimentos legítimos, das verdades, do sujeito, da naturalização e universalização dos sentidos, essas pesquisas, por um lado, expõem as arbitrariedades, os processos de criação, as historicidades e as forças que fizeram a imposição dos sentidos e, em contrapartida, criam novos sentidos e fazem a educação movimentar-se, "dançar" (Silva, 200 I).

É possível dizer, então, que as pesquisas pós-críticas em educação no Brasil têm contribuído para a conexão de campos, para o desbloqueio de conteúdos, para a proliferação de formas e para o contágio de saberes minoritários. Os sentidos são multiplicados, os conhecimentos expandidos, os espaços de criação e invenção povoados. Elas têm-se posicionado contra a fixidez de significados, de narrativas, de valores, de classificações, de subjetividades, de verdades. Sua força tem sido grande, já que desarruma muito do já pensado na educação e mostra a importância de significar de outro modo, de criar, produzir, multiplicar e proliferar nesse terreno.

Em seus múltiplos caminhos e trajetos, as pesquisas pós-críticas em educação têm feito vários deslocamentos. Fazem-nos olhar e encontrar trilhas diferentes a serem seguidas, possibilidades de transgressões em práticas que supomos permanentes, em sentidos que nos parecem fixos demais, em direções que nos parecem lineares em excesso. Aliás, em A poética e a política do currículo como representação, Silva ( 1998 a) chamou a atenção para uma atividade cara às pesquisas pós-críticas em educação: a atividade poética. Poetizar nesse caso significa produzir, fabricar, inventar, criar sentidos inéditos. Novos olhares! Novas conexões! Novas

5 Educação e Realidade, v.27, n.2, jul./dez. 2002. Esta revista é publicada pela Faculdade de Educação da Universidade Federal do Rio Grande do Sul, Porto Alegre. 
sinapses! Novos sentidos! É isto o que as produções pós-críticas têm mobilizado no campo da educação brasileira.

\section{REFERÊNCIAS BIBLIOGRÁFICAS}

AMORIN, A. C. R. Mapas desmontáveis: professores e alunos na produção de conhecimento escolar. In: REUNIÃO ANUAL DA ANPED, 24. Programa e resumos. Associação Nacional de Pós-graduação e Pesquisa em Educação, 2000. p.82-83.

BAMPI, L. R. Arte da sedução multicultural no governo do currículo. In: REUNIÃO ANUAL DAANPED, 24. Programa e resumos. p. 85. Associação Nacional de Pós-graduação e Pesquisa em Educação, 200 I . p.85.

Currículo como tecnologia de governo de cidadãos e cidadãs. Trabalho aprovado com resumo publicado na programação. In: REUNIÃO ANUAL DA ANPED, 23. Programa e resumos. p. 85. Associação Nacional de Pós-Graduação e Pesquisa em Educação, 2000. p.87.

O Currículo libertador da matemática cidadã. In: REUNIÃO ANUAL DA ANPED, 22. Programa e resumos. Associação Nacional de Pós-graduação e Pesquisa em Educação, 1999. p. 123.

BUJES, M. I. Que Infância é esta? In: REUNIÃO ANUAL DA ANPED, 23. Programa e resumos. Associação Nacional de Pós-Graduação e Pesquisa em Educação, 2000. p.94.

CARDARELLO, C. G. A Busca de uma nova erótica num currículo de formação docente. In: REUNIÃO ANUAL DA ANPED, 23. Programa e resumos. Associação Nacional de PósGraduação e Pesquisa em Educação, 2000. p.97.

CORAZZA, S. M. O Construtivismo pedagógico como significado transcendental do currículo. In: REUNIÃO ANUAL DA ANPED, 17. Programa e resumos. Associação Nacional de PósGraduação e Pesquisa em Educação, 1994. p.83.

Currículos alternativos-oficiais: o(s) risco(s) do hibridismo. In: REUNIÃO ANUAL DA ANPED, 23. Programa e textos. Associação Nacional de Pós-Graduação e Pesquisa em Educação, 2000. Disponível em: <www.anped.org.br>

Currículo como modo de subjetivação do infantil. In: REUNIÃO ANUAL DAANPED, 21. Programa e resumos. Associação Nacional de Pós-Graduação e Pesquisa em Educação, 1999. p. 143.

Currículo e política cultural da avaliação. In: REUNIÃO ANUAL DAANPED,

18. Programa e resumos. Associação Nacional de Pós-Graduação e Pesquisa em Educação, 1995. p.88. 
Labirinto da pesquisa diante dos ferrolhos. In: COSTA, M. (org.) Caminhos investigativos. novos olhares da pesquisa em educação. Porto Alegre: Mediação. 1996. p. |05-13|.

Noologia do currículo: vagamundo, o problemático, e assentado, o resolvido. In: CORAZZA, S.; E SILVA, T. Composições. Belo Horizonte: Autêntica, 2003. p. 19-34.

Olhos de poder sobre o currículo. In: REUNIÃO ANUAL DA ANPED, 24. Programa e resumos. Associação Nacional de Pós-Graduação e Pesquisa em Educação, 1996a. p. 104.

Vozes, 2001.

O Que quer um currículo?Pesquisas pós-críticas em educação. Petrópolis:

COSTA, M. Elementos para uma crítica das metodologias participativas de pesquisa. In: VEIGA-NETO, A. (org.) Crítica pós-estruturalista e educação. Porto Alegre: Sulina, 1995. p. $109-158$.

A Revista Nova Escola e a constituição da identidade feminina do magistério. In: REUNIÃO ANUAL DA ANPED, 21. Programa e resumos. Associação Nacional de Pós-Graduação e Pesquisa em Educação, 1998. p. 124.

. (org.) Caminhos investigativos. novos olhares da pesquisa em educação. Porto Alegre: Mediação, 1996. (org.) Estudos Culturais em educação. Porto Alegre: Universidade/UFRGS, 2000.

COSTA, M.; GRUN, M. A Aventura de retomar a conversação: hermenêutica e pesquisa social. In: COSTA, M. (org.) Caminhos investigativos: novos olhares da pesquisa em educação. Porto Alegre: Mediação, 1996. p.85- 104.

DELEUZE, G. Conversações. Rio de Janeiro, Ed. 34, 1992. Diferença e repetição. Rio de Janeiro: Graal, 1988.

DELEUZE, G.; GUATTARI, F. Mil Platôs: capitalismo e esquizofrenia. Rio de Janeiro: Ed. 34, 1995, v.I. Mil Platôs: capitalismo e esquizofrenia. Rio de Janeiro: Ed. 34, 1997. v.4.

DELEUZE, G.; PARNET, C. Diálogos. São Paulo: Escuta, 1998.

DONALD, J. Cheios de si, cheios de medo: os cidadãos como ciborgues. In: SILVA, T. T. (org.) Pedagogia dos monstros. os prazeres e os perigos da confusão de fronteiras. Belo Horizonte: Autêntica, 2000. p.89- 104. 
Pedagogia dos monstros: o que está em jogo nos filmes de vampiro? In: SILVA, T. T. (org.) Pedagogia dos monstros: os prazeres e os perigos da confusão de fronteiras. Belo Horizonte: Autêntica, 2000a. p. I 05- 140.

FABRIS, E. "Mr. Holland, adorável professor": uma versão hollywoodiana de espaço e tempo escolares. In: REUNIÃO ANUAL DA ANPED, 21. Programa e resumos. Associação Nacional de Pós-Graduação e Pesquisa em Educação, 1998. p. 130.

FISCHER, B. Foucault e histórias de vida: aproximações e que tais. In: REUNIÃO ANUAL DAANPED, 24. Programa e resumos. Associação Nacional de Pós-Graduação e Pesquisa em Educação, 1996. p.II4.

FISCHER, R. Análise do discurso: para além das palavras e das coisas. In: REUNIÃO ANUAL DAANPED, 17. Programa e resumos. Associação Nacional de Pós-Graduação e Pesquisa em Educação, 1994. p.98.

Estatuto pedagógico da mídia: questões de análise. In: REUNIÃO ANUAL DA ANPED, 21. Programa e resumos. Associação Nacional de Pós-Graduação e Pesquisa em Educação, 1998. p. 133.

A Paixão de "trabalhar com" Foucault. In: REUNIÃO ANUAL DA ANPED,

19. Programa e resumos. Associação Nacional de Pós-Graduação e Pesquisa em Educação, 1996. p. 114.

Uma análise foucaultiana da tv: das estratégias de subjetivação na cultura. In: REUNIÃO ANUAL DA ANPED, 24. Programa e resumos. Associação Nacional de PósGraduação e Pesquisa em Educação, 2001 . p. 117.

FRAGA, A. Bom mocismo: configuração de um modo de ser adolescente. In: REUNIÃO ANUAL DA ANPED, 21. Programa e resumos. Associação Nacional de Pós-Graduação e Pesquisa em Educação, 1998. p. 135.

GALLO, S. Conhecimento, transversalidade e currículo. In: REUNIÃO ANUAL DA ANPED, 24. Programa e resumos. Associação Nacional de Pós-Graduação e Pesquisa em Educação, 1995. p.97.

Saberes, transversalidade e poderes. In: REUNIÃO ANUAL DA ANPED,

19. Programa e resumos. Associação Nacional de Pós-Graduação e Pesquisa em Educação, 1996. p.II5.

GARCIA, M. M. A Função pastoral da pedagogia crítica. Porto Alegre, 2000. Tese (Dout.) Universidade Federal do Rio Grande do Sul.

GOMES, P. B. Princesas: figuras imaginárias na constituição de subjetividades. In: REUNIÃO ANUAL DA ANPED, 22. Programa e resumos. Associação Nacional de Pós-Graduação e Pesquisa em Educação, 1999. p. I66-167. 
GRUN, M. A produção discursiva sobre educação ambiental: terrorismo, arcaísmo e transcendentalismo. In: VEIGA-NETO, A. (org.) Crítica pós-estruturalista e educação. Porto Alegre: Sulina, 1995. p. I59-I84.

KLEIN, M. Surdez, educação e trabalho: discursos constituindo o surdo trabalhador. In: REUNIÃO ANUAL DA ANPED, 21 . Programa e resumos. Associação Nacional de Pós-Graduação e Pesquisa em Educação, 1998. p.|47-148.

KNIJNIK, G. Intelectuais, movimentos sociais e educação. In: VEIGA-NETO, A. (org.) Crítica pós-estruturalista e educação. Porto Alegre: Sulina, 1995. p.57-82.

KROEF, A. B. G. Currículo como máquina desejante. In: REUNIÃO ANUAL DA ANPED, 24. Programa e resumos. Associação Nacional de Pós-Graduação e Pesquisa em Educação, 200।. p.135-136.

LOURO, G. L. Educação e gênero: a escola e a produção do feminino e do masculino. In: SILVA, L. H.; AZEVEDO, J. C. (orgs.) Reestruturação curricular. Petrópolis: Vozes, 1995. p. $172-182$.

. Educação e gênero. In: REUNIÃO ANUAL DA ANPED, 19. Programa e resumos. Associação Nacional de Pós-Graduação e Pesquisa em Educação, 1996. p.25.

Os Estudos de gênero e a história da educação: desafios de uma proposta teórica. In: REUNIÃO ANUAL DA ANPED, 17. Programa e resumos. Associação Nacional de Pós-Graduação e Pesquisa em Educação, 1994. p. 1 24- 125.

Gênero, sexualidade e educação: uma perspectiva pós-estruturalista.

Petrópolis: Vozes, 1997.

Produzindo sujeitos masculinos e cristãos. In: REUNIÃO ANUAL DA

ANPED, 18. Programa e resumos. Associação Nacional de Pós-Graduação e Pesquisa em Educação, 1995a. p. 107.

Segredos e mentiras no currículo: sexualidade e gênero nas práticas escolares. In: SILVA, L. H. (org.) A Escola cidadã no contexto da globalização. Petrópolis: Vozes, 1998. p.33-47.

MARZOLA, N. Para uma teoria da mudança educacional. In: VEIGA-NETO, A. (org.) Crítica pós-estruturalista e educação. Porto Alegre: Sulina, 1995. p. I85-21 I.

MENDES, C. L. Currículo cultural e as ressignificações do público e do privado. In: REUNIÃO ANUAL DA ANPED, 23. Programa e resumos. Associação Nacional de Pós-Graduação e Pesquisa em Educação, 2000. p. 1 49- 150.

Duas lições para se conectar a um currículo. In: REUNIÃO ANUAL DA ANPED, 25. Programa e resumos. Associação Nacional de Pós-Graduação e Pesquisa em Educação, 2002. p. I77-। 178. 
Reforma curricular de um curso superior: relações de poder e busca de legitimidade. In: REUNIÃO ANUAL DA ANPED, 21 . Programa e resumos. Associação Nacional de Pós-Graduação e Pesquisa em Educação, 1998. p. 164.

MEYER, D. Alemão, estrangeiro, ou teuto-brasileiro? Representações de docência teutobrasileira-evangélica no Rio Grande do Sul. In: REUNIÃO ANUAL DA ANPED, 23. Programa e resumos. Associação Nacional de Pós-Graduação e Pesquisa em Educação, 2000. p. I 53.

Alguns são mais iguais que outros: etnia, raça e nação em ação no currículo escolar. In: SILVA, L. H. (org.) A Escola cidadã no contexto da globalização. Petrópolis: Vozes, 1998. p.369-380.

OGIBA, S. M. A Produção do conhecimento sobre a didática e o pós-estruturalismo: potencialidades analíticas. In: REUNIÃO ANUAL DA ANPED, 17. Programa e resumos. Associação Nacional de Pós-Graduação e Pesquisa em Educação, 1994. p. 144.

OGIBA, S. M. et al. Limites da teorização educacional moderna: implicações no campo da docência. In: REUNIÃO ANUAL DA ANPED, 19. Programa e resumos. Associação Nacional de Pós-Graduação e Pesquisa em Educação, 1996. p. 191.

PARAÍSO, M. A. O Currículo da mídia educativa: governando a subjetividade docente. In: REUNIÃO ANUAL DA ANPED, 25. Programa e resumos. Associação Nacional de PósGraduação e Pesquisa em Educação, 2002. p. 196.

Currículo e identidade: a produção de gênero, sexualidade e etnia na formação da professora. In: REUNIÃO ANUAL DA ANPED, 21 . Programa e resumos. Associação Nacional de Pós-Graduação e Pesquisa em Educação, 1998. p. 177.

Currículo, etnia e poder: o silêncio que discrimina. In: REUNIÃO ANUAL DAANPED, 20. Programa e resumos. Associação Nacional de Pós-Graduação e Pesquisa em Educação, 1997. p.|61.

. Currículo-mapa: linhas e traçados das pesquisas pós-críticas sobre currículo no Brasil. In: REUNIÃO ANUAL DA ANPED, 26. Programa e resumos. Associação Nacional de Pós-Graduação e Pesquisa em Educação, 2003. p.204.

Gênero na formação do/a professor/a: campo de silêncio do currículo? In: REUNIÃO ANUAL DA ANPED, 18. Programa e resumos. Associação Nacional de Pósgraduação e Pesquisa em Educação, 1995. p. 119.

Lutas entre culturas no currículo em ação da formação docente. Educação e Realidade, Porto Alegre, v. 21, n. I, p. 137-157, 1996.

A Produção do currículo na televisão: que discurso é esse? In: REUNIÃO ANUAL DA ANPED, 24. Programa e resumos. Associação Nacional de Pós-graduação e Pesquisa em Educação, 2000. p. 165. 
O Programa TV Escola para reformar o currículo da escola fundamental e governar o/a professor/a. In: REUNIÃO ANUAL DA ANPED, 24. Programa e resumos. Associação Nacional de Pós-Graduação e Pesquisa em Educação, 200। . p. 166.

PARENTE, R. M. Representações culturais de gênero e raça na constituição da masculinidade e do corpo dos homens do grupo afro-moçambique de Osório. In: REUNIÃO ANUAL DAANPED, 23. Programa e resumos. Associação Nacional de Pós-Graduação e Pesquisa em Educação, 2000. p. 165.

REALI, N. G. Colonos/as migrantes no currículo escolar: presença ausente. In: REUNIÃO ANUAL DA ANPED, 19. Programa e resumos. Associação Nacional de Pós-Graduação e Pesquisa em Educação, 1996. p. 150.

SANTOS, L. L. C. P. Poder e conhecimento: a constituição do saber pedagógico. In: REUNIÃO ANUAL DA ANPED, 16. Programa e resumos. Associação Nacional de Pós-Graduação e Pesquisa em Educação, 1993. p. 118.

SANTOS, S. L. A logogização do infantil: uma prática curricular. In: REUNIÃO ANUAL DA ANPED, 23. Programa e resumos. Associação Nacional de Pós-Graduação e Pesquisa em Educação, 2000. p. 185.

SILVA, T. T. O Adeus às metanarrativas educacionais. In: . (org.) O sujeito da educação: estudos foucaultianos. Petrópolis: Vozes, 1994. p. $\overline{247-258 .}$

Currículo como fetiche. In: REUNIÃO ANUAL DA ANPED, 22. Programa e resumos. Associação Nacional de Pós-Graduação e Pesquisa em Educação, 1999. p.228.

. Currículo como prática de significação. In: (org.) O Currículo como fetiche: a poética e a política do texto curricular. Belo Horizonte: Autêntica, 1999a. p.7-30.

O Currículo como representação. In: (org.) O Currículo como fetiche: a poética e a política do texto curricular. Belo Horizonte: Autêntica, 1999b. p.7-30. Currículo e identidade social: territórios contestados. In: REUNIÃO ANUAL DA ANPED, 19. Mesa redonda. Associação Nacional de Pós-Graduação e Pesquisa em Educação, 1996.

Currículo e identidades sociais: outros olhares. In: REUNIÃO ANUAL DA ANPED, 18. Programa e resumos. Associação Nacional de Pós-Graduação e Pesquisa em Educação, 1995. p. 131.

Desconstruindo o construtivismo pedagógico. Educação e Realidade, Porto Alegre, v. 18, n.2, p.3-10, jul./dez. 1993.

Dr. Nietzsche, curriculista: com uma pequena ajuda do professor Deleuze. 
In: REUNIÃO ANUAL DA ANPED, 24. Programa e resumos. Associação Nacional de PósGraduação e Pesquisa em Educação, 2001. p. 189.

Manifesto por um pensamento da diferença em educação. In: CORAZZA, S.; SILVA, T. T. Composições. Belo Horizonte: Autêntica, 2003. p.9-I8.

Monstros, ciborgues e clones: os fantasmas da pedagogia crítica. In:

(org.) Pedagogia dos monstros. os prazeres e os perigos da confusão de fronteiras. Belo Horizonte: Autêntica, 2000. p. II-22.

.Nós, ciborgues: o corpo elétrico e a dissolução do humano. In:

(org.) Antropologia do ciborgue: as vertigens do pós-humano. Belo Horizonte: Autêntica, 2000a. p.9-18.

Os Novos mapas culturais e o lugar do currículo numa paisagem pósmoderna. In: SILVA, T. T.; MOREIRA, A. F. (orgs.) Territórios contestados: o currículo e os novos mapas políticos e culturais. Petrópolis: Vozes, 1995a. p. 184-202.

As Pedagogias psi e o governo do eu nos regimes neoliberais. In:

(org.) Liberdades reguladas: a pedagogia construtivista e outras formas de governo do eu. Petrópolis: Vozes, 1998. p. 7-13.

A Poética e a política do currículo como representação. In: REUNIÃO ANUAL DA ANPED, 21 . Programa e resumos. Associação Nacional de Pós-Graduação e Pesquisa em Educação, 1998a. p. 199.

. A Produção social da identidade e da diferença. In: (org.) /dentidade e diferença: a perspectiva dos estudos culturais. Petrópolis: Vozes, 2000b. p. 73- 102.

O Projeto educacional moderno: identidade terminal? In: VEIGA-NETO, A. (org.) Crítica pós-estruturalista e educação. Porto Alegre: Sulina, 1995b. p.245-260.

Sociologia da educação e pedagogia crítica em tempos pós-modernos In: REUNIÃO ANUAL DA ANPED, 16. Programa e resumos. Associação Nacional de Pósgraduação e Pesquisa em Educação, 1993a. p. 122.

(org.) Alienígenas na sala de aula: uma introdução aos estudos culturais em educação. Petrópolis: Vozes, 1995c.

(org.) Liberdades reguladas: a pedagogia construtivista e outras formas de governo do eu. Petrópolis: Vozes, 1998b.

(org.) Nunca fomos humanos: nos rastros do sujeito. Belo Horizonte: Autêntica, 200la.

(org.) O Sujeito da educação: estudos foucaultianos. Petrópolis: Vozes, 1994a. 
(org.) Teoria educacional crítica em tempos pós-modernos. Porto Alegre:

Artes Médicas, 1993b.

SOMMER, L. H. Informática educativa e currículo: materialidade pós-moderna e racionalidade moderna. In: REUNIÃO ANUAL DAANPED, 23. Programa e resumos. Associação Nacional de Pós-Graduação e Pesquisa em Educação, 2000. p. 196.

STEPHANOU, M. Governar ensinando a governar-se: discurso médico e educação. In: REUNIÃO ANUAL DA ANPED, 21. Programa e resumos. Associação Nacional de PósGraduação e Pesquisa em Educação, 1998. p.210.

UBERTI, L. "Diário de um bebê": economia de governo na política de subjetividade da infância. In: REUNIÃO ANUAL DA ANPED, 26. Programa e resumos. Associação Nacional de Pós-Graduação e Pesquisa em Educação, 2003. p.203.

A Sujeição moral do infantil-cidadão no currículo nacional. In: REUNIÃO ANUAL DA ANPED, 23. Programa e resumos. Associação Nacional de Pós-Graduação e Pesquisa em Educação, 2000. p.202.

VEIGA-NETO, A. Foucault e educação. In: REUNIÃO ANUAL DA ANPED, 19. Programa e resumos. Associação Nacional de Pós-Graduação e Pesquisa em Educação, 1996. p.24.

Foucault e educação: outros estudos foucaultianos. In: SILVA, T. T. (org.) $O$ Sujeito da educação: estudos foucaultianos. Petrópolis: Vozes, 1994. p.225-246.

Michel Foucault e educação: há algo de novo sob o sol? In: (org.) Crítica pós-estruturalista e educação. Porto Alegre: Sulina, 1995. p.9-56

Michel Foucault e os estudos culturais. In: COSTA, M. (org.) Estudos culturais em educação. Porto Alegre: Universidade/UFRGS, 2000. p.37-72.

Recebido em: janeiro 2004

Aprovado para publicação em: março 2004 